\title{
The E2F4 prognostic signature is also predictive of the pathological response of breast cancer to chemotherapy
}

\author{
François Bertucci ${ }^{1,2,3^{*}}$, Pascal Finetti ${ }^{1}$ and Daniel Birnbaum ${ }^{1}$ \\ See related research by Khaleel et al., http://breast-cancer-research.com/content/16/6/486
}

We read with interest the article by Khaleel and colleagues reporting a new prognostic signature in hormone receptor (HR)-positive breast cancer based on mRNA expression of target genes of the E2F4 transcription factor [1]. The clinical relevance comes from its independent prognostic value and its biological significance (mainly regulation of cell cycle and proliferation, reflecting high E2F4 activity). When compared with patients with low score for the signature (low risk), patients with high score (high risk) showed shorter relapse-free survival, making them candidates for adjuvant chemotherapy. Whereas adjuvant chemotherapy is recommended for most human epidermal growth factor receptor 2 (HER2)-positive or triple-negative tumors, indications are more challenging for $\mathrm{HR}^{+} / \mathrm{HER} 2^{-}$ tumors, which are candidates for either adjuvant hormone therapy alone or both hormone therapy and chemotherapy.

We wondered whether high-risk $\mathrm{HR}^{+} / \mathrm{HER} 2^{-}$tumors were more chemosensitive than low-risk $\mathrm{HR}^{+} / \mathrm{HER} 2^{-}$ tumors. We gathered gene expression data for 1,247 breast cancers treated with neoadjuvant anthracyclinebased chemotherapy and with available pathological response (Additional file 1), pathological complete response (pCR) being defined as no residual invasive cancer in the breast and axillary lymph nodes. All cases were assigned a relapse risk according to the metagene based on average expression of 199 E2F4 target genes in each standardized dataset. We analyzed the predictive value of the E2F4 metagene for the pathological response to chemotherapy in the $582 \mathrm{HR}^{+} / \mathrm{HER} 2^{-}$tumors (12\% pCR rate). High-risk tumors were associated (Additional file 2) with ductal type, grade 3 , and higher pCR rate, which was $17 \%$ versus $8 \%$ in the low-risk tumors $(P<0.001)$. As expected, grade 3 was also associated with higher $\mathrm{pCR}$ rate (Table 1 ). In multivariate analysis, the E2F4 metagene remained predictive for $\mathrm{pCR}(P=0.027)$, whereas grade did not. Interestingly, mRNA expression of E2F4 itself did not predict for the response to chemotherapy, demonstrating the interest of the metagene as a better indicator of E2F4 function than E2F4 expression level alone.

$\mathrm{HR}^{+} / \mathrm{HER} 2^{-}$tumors with an E2F4 high-risk signature were more sensitive to anthracycline-based chemotherapy than low-risk tumors, as already reported with other prognostic signatures $[2,3]$ - including in the adjuvant setting $[4,5]$, where high-risk tumors showed greater benefit from chemotherapy than low-risk tumors. The next step will be to test, retrospectively in randomized prospective trials of adjuvant chemotherapy, the hypothesis that the difference in relapse between patients treated with chemotherapy and untreated patients is larger in the high-risk group than in the low-risk group. Interest in the E2F4 signature is probably higher than expected.

\footnotetext{
* Correspondence: bertuccif@ipc.unicancer.fr

${ }^{1}$ Département d'Oncologie Moléculaire, Centre de Recherche en

Cancérologie de Marseille, Institut Paoli-Calmettes, UMR1068 Inserm, 232 boulevard de Sainte-Marguerite, 13009 Marseille, France

²Département d'Oncologie Médicale, Centre de Recherche en Cancérologie de Marseille, Institut Paoli-Calmettes, UMR1068 Inserm, 232 boulevard de Sainte-Marguerite, 13009 Marseille, France

Full list of author information is available at the end of the article
}

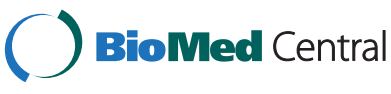

(C) 2015 Bertucci et al.; licensee BioMed Central. This is an Open Access article distributed under the terms of the Creative Commons Attribution License (http://creativecommons.org/licenses/by/4.0), which permits unrestricted use, distribution, and reproduction in any medium, provided the original work is properly credited. The Creative Commons Public Domain Dedication waiver (http://creativecommons.org/publicdomain/zero/1.0/) applies to the data made available in this article, unless otherwise stated. 
Table 1 Univariate and multivariate analyses for pathological complete response

\begin{tabular}{|c|c|c|c|c|c|c|}
\hline & \multicolumn{3}{|c|}{ Univariate analysis } & \multicolumn{3}{|c|}{ Multivariate analysis } \\
\hline & $\bar{n}$ & Odds ratio $(95 \% \mathrm{Cl})$ & $P$ value & $\bar{n}$ & Odds ratio $(95 \% \mathrm{Cl})$ & $P$ value \\
\hline Age, $>50$ years versus $\leq 50$ years & 582 & 0.79 (0.51 to 1.21$)$ & 0.37 & & & \\
\hline \multicolumn{7}{|l|}{ Histological type } \\
\hline ILC versus IDC & 240 & 2.60 (0.71 to 8.12$)$ & 0.19 & & & \\
\hline Other versus IDC & & 1.09 (0.49 to 2.26$)$ & 0.85 & & & \\
\hline Clinical tumor size, cT2 to cT4 versus CT1 & 580 & 0.88 (0.44 to 2.01$)$ & 0.79 & & & \\
\hline Clinical axillary lymph node status, $\mathrm{CN} 1$ to $\mathrm{CN} 3$ versus $\mathrm{CNO}$ & 571 & $1.37(0.86$ to 2.23$)$ & 0.27 & & & \\
\hline \multicolumn{7}{|l|}{ Grade } \\
\hline 2 versus 1 & 529 & $1.32(0.43$ to 5.98$)$ & 0.72 & 529 & $1.22(0.40$ to 5.52$)$ & 0.80 \\
\hline 3 versus 1 & & 5.56 (1.93 to 24.4$)$ & $2.09 \mathrm{E}-02$ & & 4.37 (1.48 to 19.4$)$ & 0.05 \\
\hline E2F4 metagene-based classification, high risk versus low risk & 582 & 2.40 (1.57 to 3.72$)$ & 7.98E-04 & 529 & $1.86(1.14$ to 3.08$)$ & 4.02E-02 \\
\hline
\end{tabular}

$\mathrm{Cl}$, confidence interval; IDC, invasive ductal cancer; ILC, invasive lobular cancer. Bold data indicate significance.

\section{Additional files}

Additional file 1: Table S1. Presenting a description of the eight public breast cancer datasets.

Additional file 2: Table S2. Presenting the E2F4 metagene-based classification and clinicopathological correlations.

\section{Abbreviations}

HER2: Human epidermal growth factor receptor 2; HR: Hormone receptor; pCR: Pathological complete response.

\section{Competing interests}

The authors declare that they have no competing interests.

\section{Authors' contributions}

FB designed the study. FB and PF performed the analyses. FB wrote the manuscript. PF and DB revised the manuscript. All authors approved submission of the manuscript.

\section{Acknowledgements}

This work is supported by Institut Paoli-Calmettes, Inserm, Institut National du Cancer (AOPL2010 IVOIRES), Ligue Nationale contre le Cancer (label DB) and SIRIC INCa-DGOS-Inserm 6038.

\section{Author details}

'Département d'Oncologie Moléculaire, Centre de Recherche en Cancérologie de Marseille, Institut Paoli-Calmettes, UMR1068 Inserm, 232 boulevard de Sainte-Marguerite, 13009 Marseille, France. ${ }^{2}$ Département d'Oncologie Médicale, Centre de Recherche en Cancérologie de Marseille, Institut Paoli-Calmettes, UMR1068 Inserm, 232 boulevard de

Sainte-Marguerite, 13009 Marseille, France. ${ }^{3}$ Faculté de Médecine, 13385

Aix-Marseille Université, 27 boulevard Jean Moulin, Marseille cedex 5, France.

\section{Published online: 10 April 2015}

\section{References}

1. Khaleel SS, Andrews EH, Ung M, Direnzo J, Cheng C. E2F4 regulatory program predicts patient survival prognosis in breast cancer. Breast Cancer Res. 2014;16:486

2. Liedtke C, Hatzis C, Symmans WF, Desmedt C, Haibe-Kains B, Valero V, et al. Genomic grade index is associated with response to chemotherapy in patients with breast cancer. J Clin Oncol. 2009;27:3185-91.

3. Bertucci F, Finetti $P$, Viens $P$, Birnbaum D. EndoPredict predicts for the response to neoadjuvant chemotherapy in ER-positive, HER2-negative breast cancer. Cancer Lett. 2014;355:70-5.
4. Paik S, Tang G, Shak S, Kim C, Baker J, Kim W, et al. Gene expression and benefit of chemotherapy in women with node-negative, estrogen receptorpositive breast cancer. J Clin Oncol. 2006;24:3726-34.

5. Knauer M, Mook S, Rutgers EJ, Bender RA, Hauptmann M, van de Vijver MJ, et al. The predictive value of the 70-gene signature for adjuvant chemotherapy in early breast cancer. Breast Cancer Res Treat. 2010;120:655-61. 